\title{
Estudio seroepidemiológico del cólera en Colombia
}

\author{
Magaly Chinchilla, Fernando de la Hoz, Elizabeth Castañeda
}

\begin{abstract}
Resumen
La prueba vibriocida ha sido ampliamente usada para confirmar el diagnóstico clínico de cólera, para medir la inmunogenicidad de las posibles vacunas y como herramienta epidemiológica en estudios de la enfermedad en áreas endémicas y en brotes. A partir de marzo de 1991, Colombia se vió afectada por la primera epidemia de cólera en este siglo; por esta razón, para obtener información adicional sobre el alcance de la epidemia en nuestro medio se planeó la realización de un estudio descriptivo con métodos seroepidemiológicos. Se empleó la prueba vibriocida en micrométodo, con las cepas de Vibrio cholerae O1 El Tor Inaba y El Tor Ogawa, y se definió como resultado reactivo un título mayor o igual a 80 y como infección reciente un título mayor o igual a 640 . La población estudiada estaba conformada por 73 pacientes con enfermedad diarreica aguda y por 4.577 consultantes por otras causas. Se procesaron 4.650 sueros de 5 de las 6 regiones del país, afectadas por la epidemia, 1.520 obtenidas en 1991, 1.229 en 1992 y 1.901 en 1993 . Del total, $21,5 \%$ fueron reactivas, $25 \%$ en $1991,21,4 \%$ en 1992 y $19 \%$ en 1993. El porcentaje de reactividad global en hombres fue de $24 \%$ y en mujeres, de $20 \%$. No se encontraron diferencias en el porcentaje de reactividad según la distribución por edad. El porcentaje de infección reciente fue de 10\%. En los pacientes con diagnóstico de cólera, la prevalencia de infección determinada por la reactividad en la prueba vibriocida fue de $68,5 \%$ y de infección reciente de $51 \%$. El análisis de los resultados de las regiones pacífica y atlántica fue consistente con la evolución epidemiológica de los casos clínicos de cólera en esas regiones.
\end{abstract}

\section{Summary}

The vibriocidal test has been widely used to confirm clinical cases of cholera, to measure immunogenicity of possible vaccines and as an epidemiological tool to study diseases in endemic areas as well as in outbreaks. In March 1991, Colombia was affected by the first cholera epidemic in this century. The aim of this study was therefore to obtain additional information concerning the magnitude of epidemics in our country using a serological test. Vibriocidal antibodies were measured, using micromethodology, on Vibrio cholerae 01, El Tor Inaba and El Tor Ogawa strains. A reactive result was defined as that obtained from titres greater or equal to 80 and recent infection was established if a titre was greater than or equal to 640 . Serum samples were studied from 73 patients with diarrhoea and from 4,577 patients who had consulted regional hospitals for other reasons. The samples were obtained from 5 of those 6 rural areas affected by the epidemics; 1,520 were obtained in $1991,1,229$ in 1992 and 1,901 in 1993 . Overall reactivity was $21.5 \% ; 25 \%$ in 1991 , $21.4 \%$ in 1992 and $19 \%$ in 1993 . Regarding gender, reactivity was $24 \%$ in males and $20 \%$ in females; no age group differences were encountered. Recent infection was determined in $10 \%$ of the cases. In cholera patients, infection prevalence (determined by serum reactivity) was $68.5 \%$ and recent infection prevalence was $51 \%$. Vibriocidal results from the Pacific and Atlantic regions showed a very high correlation with clinical cholera cases' epidemiological evolution. 
Vibrio cholerae 01, agente del cólera, tiene la capacidad de inducir en el hospedero una respuesta antibacteriana dirigida contra el antígeno somático $\mathrm{O}$, las proteínas de membrana y la subunidad $B$ de la toxina del cólera $(1,2)$. Una variedad de métodos han sido empleados para medir esta respuesta inmune humoral, tal vez los más sencillos y reproducibles son la aglutinación y la técnica vibriocida (3).

La determinación de anticuerpos en el suero tiene gran valor debido a que permite establecer controles en los estudios de casos-controles, identificar casos sospechosos de cólera en personas en quienes no se han tomado los cultivos adecuados, medir la proporción de personas que han sido infectadas en las zonas recién afectadas y realizar estudios restrospectivos en colecciones de sueros, para establecer si el cólera ha pasado inadvertido en una región determinada (4).

Específicamente, la prueba vibriocida ha sido ampliamente usada en encuestas para confirmar el diagnóstico clínico del cólera, para medir la inmunogenicidad de las posibles vacunas (5-9) y como herramienta epidemiológica en estudios de la enfermedad en áreas endémicas (2).

Los anticuerpos vibriocidas son principalmente de la clase $\lg G(10)$, se producen a los 7 días de haberse iniciado la infección y permanecen por un período de 6 meses (11). Los anticuerpos antitoxina son de las clases IgG e $\lg A$ y se mantienen por períodos más largos (12).

Está descrito que, en áreas endémicas, 20 a 50\% de la población presenta un título de anticuerpos vibriocidas mayor o igual a 1:160; por el contrario, en las áreas no endémicas, estos anticuerpos pueden determinarse en menos de $10 \%$ de la población (2).

A partir de marzo de 1991, Colombia se vió afectada por la primera epidemia de cólera en este siglo (13). Para obtener información adicional sobre el alcance de la epidemia en nuestro medio, se planeó la realización de un estudio descriptivo con el empleo de métodos seroepidemiológicos. Este estudio se realizó en una población de pacientes con diagnóstico clínico de cólera y en asintomáticos, procedentes todos ellos, de cinco regiones del país afectadas por la epidemia.

\section{Materiales y métodos}

Muestras. Se procesaron 4.650 sueros, obtenidos de 1991 a 1993, de personas de las cinco regiones de país afectadas por la epidemia. De estos sueros, 4.577 provenían de la consulta general de los hospitales y 73 de pacientes con diagnóstico clínico de cólera.

Técnica vibriocida. Se realizó la prueba con el micrométodo estandarizado en la Universidad de Goteborg, Suecia (14). Brevemente, se emplearon microplacas de poliestireno, fondo en $U$, de 96 pozos (Costar, Cambrigde, MA), una cepa de Vibrio cholerae O1, El Tor Inaba (T19479) y un exceso de complemento de cobayo (Sigma, St. Louis, Missouri). Como control reactivo, se empleó un suero de conejo inmunizado (R1072) con $V$. cholerae $\mathrm{O1}$, con un título de anticuerpos de 1:4.000 (donado por A.M. Svennerholm, Universidad de Goteborg, Suecia). En un número de sueros no reactivos, se realizó la prueba con el empleo de una cepa de V. cholerae O1, EI Tor Ogawa (INS 1028).

El inóculo de $V$. cholerae 01 se estandarizó con una $\mathrm{DO}=0,2$ a $550 \mathrm{~nm}$. Los sueros se inactivaron por 30 minutos a $56^{\circ} \mathrm{C}$ y se analizaron en diluciones dobles seriadas. La reactividad se interpretó como el recíproco de la dilución del suero que inhibió completamente el crecimiento de la bacteria y se expresó como título.

Definiciones. Se definió como paciente infectado aquél que presentó una reactividad en el suero con un título mayor o igual a 80 para cualquier serotipo (Inaba, Ogawa). Para estimar el punto de corte de la reactividad de los títulos, se calculó el promedio geométrico y la desviación estándar de los títulos vibriocidas de 408 sueros prevacunales de un ensayo de seguridad e inmunogenicidad de una vacuna oral (5) y de 322 sueros preepidemia recolectados dos meses antes del diagnóstico de casos de cólera en la región atlántica. Se calculó el logaritmo de los títulos y se consideró como valor de corte el promedio geométrico más dos desviaciones estándar de esta muestra (15).

Se definió como paciente con infección reciente, el que presentó títulos vibriocidas mayores o iguales a 1:640. 
Casos clínicos. Los datos de las tasas de incidencia de cólera de los diferentes departamentos que participaron en el estudio, se obtuvieron de los boletines epidemiológicos del Ministerio de Salud de Colombia (Informe del Ministerio de Salud, Oficina de Prevención y Desastres).

Análisis estadístico. Se calculó la prevalencia de infectados y de infección reciente. Se compararon estas prevalencias por grupos de edad, sexo y por regiones. Se utilizó la prueba chi $^{2}$ y las asociaciones se midieron en razones de prevalencia (RP) y sus intervalos de confianza (IC 95\%) (16). Así mismo, se comparó la prevalencia de infección y de infección reciente entre los pacientes con diagnóstico clínico de cólera $(n=73)$ y los de un grupo de asintomáticos $(n=949)$ que consultaron al mismo hospital de la región pacífica, en la misma época. Se utilizó la razón de prevalencia de Mantel y Haentzel para ajustar por edad y por género las diferencias encontradas (16).

\section{Resultados}

Procedencia de los sueros. Se procesaron 4.650 sueros, 1.520 obtenidos en 1991, 1.229 en 1992 y 1.901 en 1993. De estos sueros, 2.154 fueron obtenidos en la región pacífica, departamentos de Nariño, Chocó, Valle y Cauca; 1.656 en la región atlántica, departamentos de Atlántico, La Guajira, Magdalena y San Andrés; 474 en la región andina, departamentos de Caldas, Huila y Tolima; 132 en la Amazonia y 95 en la región oriental, departamento de Norte de Santander. Adicionalmente, se procesaron 139 sueros de otras regiones (figura 1).
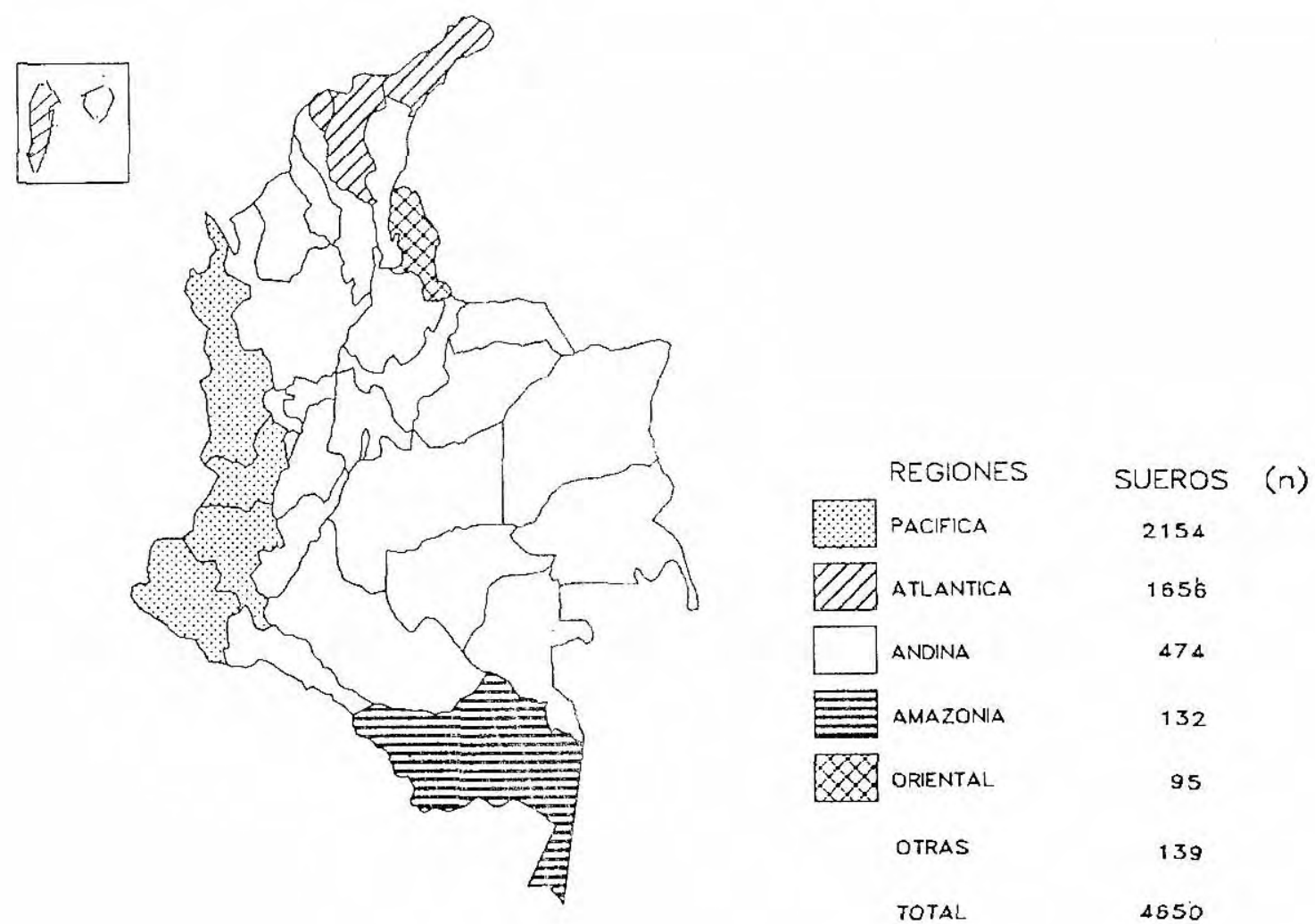

Figura 1. Regiones donde se realizó el estudio seroepidemiológico de cólera (1991-1993). 
Reactividad. En el cuadro 1 se presentan los porcentajes de reactividad de la prueba vibriocida por región y por año de observación. A través de los tres años del estudio, la prevalencia general de infección fue de 21,5 , para la región pacífica de $26,5 \%$ y para las otras regiones de $6,4 \%$.

La prevalencia de infección reciente (título vibriocida mayor o igual a 640 ) fue de $10 \%$, discriminada por región y por año de la siguiente manera: en la región pacífica de $18 \%(142 / 775)$ en 1991 , de $4 \%$ (21/575) en 1992 y de $0,5 \%$ (4/ $800)$ en 1993 y en la región atlántica de 1,7\% (7/ $410), 7,5 \%(17 / 226)$ y $0,7 \%(7 / 1.020)$ en los mismos años, respectivamente.

Reactividad con el serotipo Ogawa. Al emplear la cepa de $V$. cholerae 01 serotipo Ogawa en la prueba vibriocida, el porcentaje de reactividad de los sueros no reactivos con el serotipo Inaba, se incrementó en $7 \%$.

Reactividad por género y por grupos de edad. De las 4.650 muestras analizadas, se obtuvieron datos del género en 3.676 y de la edad en 2.783 . En el cuadro 2 se informa la prevalencia de reactividad por año, en relación con el género y los grupos de edad. La prevalencia para el género masculino fue de $24 \%(316 / 1.298)$ y para el femenino de $20 \%$ (470/2.378) (RP=1,2; IC 95\% 1,09-1,4). Solamente en 1991, la prevalencia de reactividad por género fue significativamente mayor en hombres que en mujeres (RP=1,4; IC 95\% 1,21,7). En general, se observó una disminución en la prevalencia de infección en los cuatro grupos de edad durante los tres años estudiados.
Al analizar las variables de género y de edad, la prevalencia de infección se comportó de manera diferente para ambos géneros. En los hombres, la prevalencia de infección se incrementó de 19\% en menores de 5 años, a $30 \%$ en mayores de 45 años ( $p=0,01)$; pero, en las mujeres, en los mismos grupos de edad, la diferencia no fue significativa $(p=0,6)$. Al estratificar por grupos de edad, se mantuvo la diferencia por género.

Infección reciente por género y por grupos de edad. La prevalencia de infección reciente para el género masculino fue de $8 \%(103 / 1.298)$ y para el femenino de $4 \%$ (RP=1,9; IC 95\% 1,5-2,5). En los cuatro grupos de edad, se observó una disminución en la prevalencia de infección reciente durante los tres años de estudio (cuadro 3).

Pacientes con diagnóstico clínico de cólera. En el análisis de las 73 muestras con diagnóstico clínico de cólera, la prevalencia de infección fue de $68,5 \%$ (50/73). Según el género fue de $68,6 \%$ (24/35) para el masculino y de $67,6 \%$ (25/37) para el femenino. Teniendo en cuenta los cuatro grupos de edad, la prevalencia de infección fue de $60 \%$ (3/5) para el grupo de $1-4$ años, de $78 \%$ (7/9) para el grupo de $5-14$ años, de $74 \%$ (25/34) y de $64 \%$ (9/14) para el grupo de 15-44 años y mayores de 45 años, respectivamente.

La prevalencia de infección reciente en estos pacientes fue de $51 \%$ (37/73) y según el género fue de $54,3 \%$ (19/35) para el masculino y de $51,4 \%$ (19/37) para el femenino. De acuerdo con el grupo de edad fue de $40 \%$ (2/5), $78 \%$ (7/9), $53 \%$ (18/ $34), 50 \%$ (7/14) para los grupos de $1-4$ años, $5-14$

Cuadro 1. Porcentajes de reactividad de la prueba vibriocida, por región y por año.

\begin{tabular}{|c|c|c|c|c|c|c|c|c|c|c|c|}
\hline \multirow[t]{3}{*}{ REGION } & \multicolumn{3}{|c|}{1991} & \multicolumn{3}{|c|}{1992} & \multicolumn{3}{|c|}{1993} & \multicolumn{2}{|c|}{ TOTAL } \\
\hline & \multirow[t]{2}{*}{$n$} & \multicolumn{2}{|c|}{ Reactividad } & \multirow[t]{2}{*}{$\mathbf{n}$} & \multicolumn{2}{|c|}{ Reactividad } & \multirow[t]{2}{*}{$n$} & \multicolumn{2}{|c|}{ Reactividad } & \multicolumn{2}{|c|}{ Reactividad } \\
\hline & & $n$ & $\%$ & & $n$ & $\%$ & & $n$ & $\%$ & $n$ & $\%$ \\
\hline Pacífica & 77 & 252 & $(32,5)$ & 577 & 179 & (31) & 803 & 141 & $(17,5)$ & 2.154 & $(26,5)$ \\
\hline Atlántica & 410 & 22 & $(17,5)$ & 226 & 63 & $(27,6)$ & 1020 & 205 & $(20,0)$ & 1.656 & $(20,5)$ \\
\hline Amazonia & 132 & 19 & $(14,4)$ & 0 & 0 & (0) & 0 & 0 & $(0)$ & 132 & $(14,4)$ \\
\hline Andina & 88 & 28 & $(31,8)$ & 361 & 20 & $(5,5)$ & 25 & 2 & $(8,0)$ & 474 & 10,5 \\
\hline Oriente & 29 & 2 & $(6,8)$ & 16 & 0 & (0) & 0 & 10 & $20,0)$ & 95 & $(12,6)$ \\
\hline Otras & 87 & 7 & $(8,0)$ & 49 & 2 & $(4,0)$ & 3 & 0 & $(0)$ & 139 & $(6,4)$ \\
\hline Total & 1520 & 380 & $(25,0)$ & 1229 & 264 & $(21,4)$ & 1901 & 356 & $(19,0)$ & 4.650 & $(21,5)$ \\
\hline
\end{tabular}


Cuadro 2. Prevalencia de infección expresada como reactividad de la prueba vibriocida por año, en relación con el género y los grupos de edad.

\begin{tabular}{|c|c|c|c|c|c|c|c|c|c|c|c|c|}
\hline 1. Genero & $\mathrm{n}$ & $\begin{array}{c}19 \\
\text { Rea } \\
n\end{array}$ & $\begin{array}{l}991 \\
\text { actividad } \\
(\%)\end{array}$ & n & $\begin{array}{c}195 \\
\text { Reac } \\
n\end{array}$ & $\begin{array}{l}92 \\
(\%)\end{array}$ & $n$ & $\begin{array}{c}19 \\
\text { Reac } \\
\text { n }\end{array}$ & $\begin{array}{l}93 \\
\text { ctividad } \\
(\%)\end{array}$ & $\mathrm{n}$ & $\begin{array}{c}\text { TOTA } \\
\text { Reac } \\
\text { n }\end{array}$ & $\begin{array}{l}\text { tividad } \\
(\%)\end{array}$ \\
\hline Masculino & 561 & 174 & $(31)^{*}$ & 485 & 105 & (22) & 252 & 37 & (15) & 1298 & 316 & (24) \\
\hline Femenino & 862 & 192 & (22) & 682 & 137 & (20) & 834 & 141 & $(17)$ & 2378 & 470 & (20) \\
\hline Total & 1423 & 366 & (26) & 1167 & 242 & $(21)$ & 1086 & 178 & (16) & 3676 & 786 & $(21,4)$ \\
\hline \multicolumn{13}{|c|}{ 2. Grupos de edad } \\
\hline $1-4$ & 32 & 9 & $(28)$ & 25 & 4 & $(16)$ & 11 & 0 & $(0)^{\star \star}$ & 68 & 13 & $(19)$ \\
\hline $5-14$ & 90 & 31 & $\langle 34,4\rangle$ & 49 & 10 & $\langle 20,4\rangle$ & 46 & 8 & $(17,4)$ & 185 & 49 & $(26,4)$ \\
\hline $15-44$ & 719 & 175 & $(24,3)$ & 474 & 125 & $(26,4)$ & 620 & 103 & $(16,6)$ & 1813 & 403 & (22) \\
\hline$>44$ & 234 & 69 & $(26,4)$ & 229 & 69 & $(30,1)$ & 252 & 46( & $18,3)$ & 715 & 184 & $(25,7)$ \\
\hline Total & 1075 & 284 & $(26,4)$ & 777 & 208 & $(26,7)$ & 931 & 157 & $(16,6)$ & 2783 & 649 & $(23,3)$ \\
\hline
\end{tabular}

$p<0,001 P<0,05$

$* p<0,05$

Cuadro 3. Prevalencia de infección reciente expresada como reactividad de la prueba vibriocida por año en relación con el género y grupos de edad.

\begin{tabular}{|c|c|c|c|c|c|c|c|c|c|c|c|c|}
\hline \multirow{2}{*}{$\begin{array}{l}\text { 1. GENERO } \\
\text { Masculino }\end{array}$} & \multirow{2}{*}{$\begin{array}{c}n \\
561\end{array}$} & \multicolumn{2}{|c|}{$\begin{array}{l}1991 \\
\text { Reactividad } \\
\mathrm{n} \quad(\%)\end{array}$} & $n$ & \multicolumn{2}{|c|}{$\begin{array}{l}1992 \\
\text { Reactividad } \\
n \quad(\%)\end{array}$} & $\mathrm{n}$ & \multicolumn{2}{|c|}{$\begin{array}{l}1993 \\
\text { Reactividad } \\
n \quad(\%)\end{array}$} & $\mathrm{n}$ & \multicolumn{2}{|c|}{$\begin{array}{l}\text { TOTAL } \\
\text { Reactividad } \\
n \quad(\%)\end{array}$} \\
\hline & & 83 & $(15)^{\star}$ & 485 & 20 & $(4)^{\star *}$ & 252 & 0 & (0) & 1298 & 103 & (8) \\
\hline Femenino & 862 & 76 & (9) & 682 & 14 & (2) & 834 & 8 & (1) & 2378 & 98 & (4) \\
\hline Total & 1423 & 159 & (11) & 1167 & 34 & (3) & 1086 & 8 & $(0,7)$ & 3676 & 201 & $(5,4)$ \\
\hline \multicolumn{13}{|c|}{ 2. Grupos de edad } \\
\hline $1-4$ & 32 & 6 & $(18,8)^{* * *}$ & 250 & 0 & $(0)^{\star \star \star}$ & 11 & 0 & 10 & $\longdiv { 6 8 }$ & 6 & $(8,8)$ \\
\hline $5-14$ & 90 & 24 & $(26,7)$ & 49 & 3 & $(6,1)$ & 46 & 0 & (0) & 185 & 27 & $(14,6)$ \\
\hline $15-44$ & 719 & 58 & $(8,1)$ & 474 & 23 & (5) & 620 & 6 & (1) & 1813 & 87 & $(4,8)$ \\
\hline$>44$ & 234 & 32 & $(13,7)$ & 229 & 5 & $(2,2)$ & 252 & 2 & $(0,8)$ & 715 & 39 & $(5,5)$ \\
\hline Total & 1075 & 120 & $(11,1)$ & 777 & 31 & (4) & 931 & 8 & $(0,9)$ & 2783 & 159 & $(5,7)$ \\
\hline
\end{tabular}

$p<0,001$

$p<0,05$

" $p<0,01$

años, 15-44 años y mayores de 45 año, respectivamente.

La probabilidad de haberse infectado con $V$. cholerae $\mathrm{O} 1$ fue tres veces mayor entre los casos clínicos de cólera, comparado con las otras personas asintomáticas que consultaron al laboratorio del hospital en la misma época (RP=2,7; IC 95\% 2,3-3,3). La probabilidad de haberse infectado recientemente fue cinco veces mayor entre los casos clínicos $(R P=5,5 ;$ iC 95\% $4,2-7,3)$. Al estratificar por sexo y edad no se modificaron las asociaciones en forma importante.
Correlación con la tasa de ataque de enfermedad. En las figuras 2A-2D, se presenta la correlación entre el porcentaje de reactividad de la prueba vibriocida, con la tasa/1.000 de casos de cólera informados al Ministerio de Salud por las diferentes regiones estudiadas. Se observa que, en las regiones pacífica y atlántica, el aumento o disminución de los títulos vibriocidas coincidió con el aumento o disminución en las tasas de ataque de la enfermedad clínica durante 1991 a 1993. 
Fig. 2A-D. Correlación de porcentaje de reactividad de la prueba vibriocida con la tasa de casos clínicos de cólera.

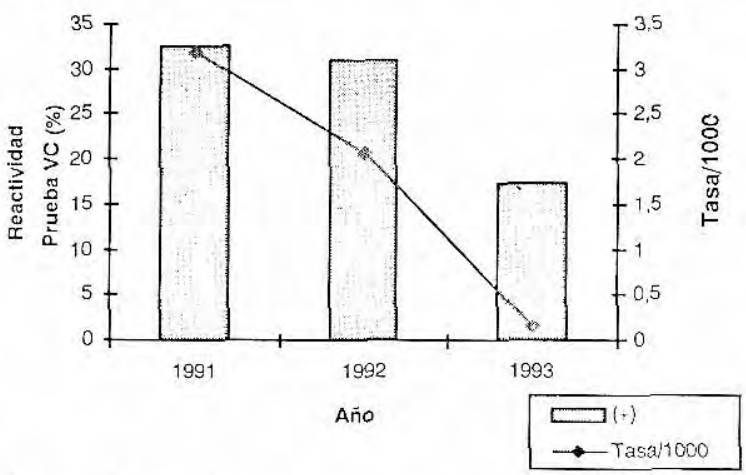

A: región Pacífica

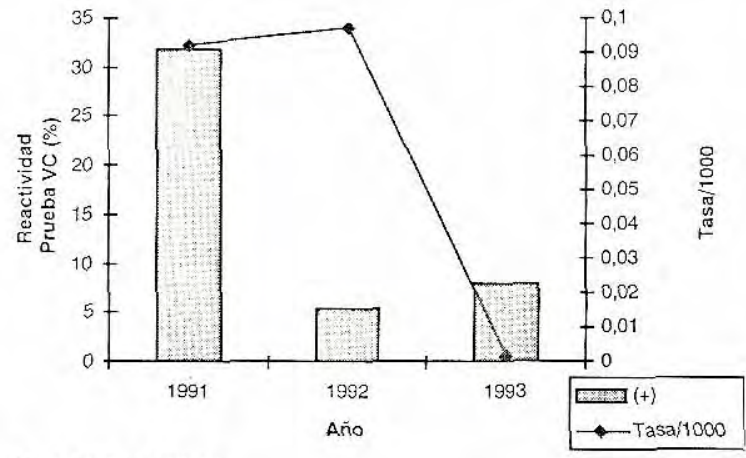

C: región Andina

\section{Discusión}

La presencia de anticuerpos vibriocidas en el suero de los pacientes o un incremento de cuatro diluciones en el título de muestras tomadas en dos fases de la enfermedad (aguda y convaleciente), se ha empleado ampliamentecomo una evidencia indirecta en el diagnóstico del cólera $(3-6,12)$, dado que el cultivo, evidencia directa, no siempre puede realizarse. Adicionalmente, la determinación de anticuerpos en una población afectada por el cólera pone de manifiesto las infecciones asintomáticas o con sintomatología leve lo que da una idea real del alcance de un brote o de una epidemia en una región determinada $(7,17)$.

En áreas endémicas, existe una relación inversa entre la tasa de ataque de $V$. cholerae 01 y la edad; la mayor incidencia de la enfermedad se presenta en menores de 4 años, debido a que esta población no ha tenido exposición previa (18), mientras que los adultos son inmunes a la infección

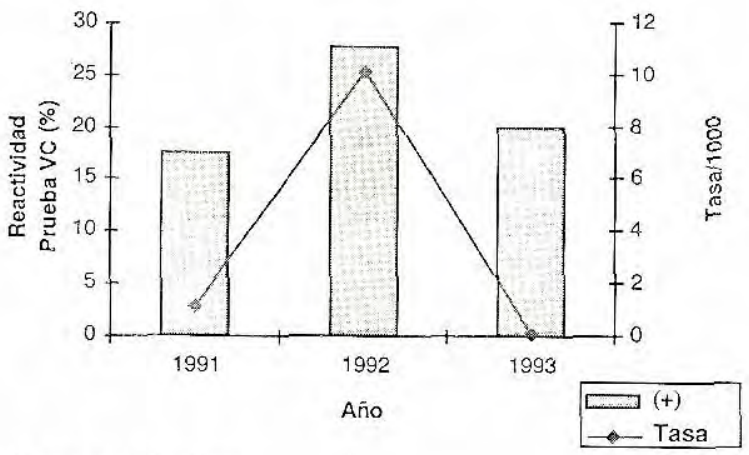

B: región Atlántica

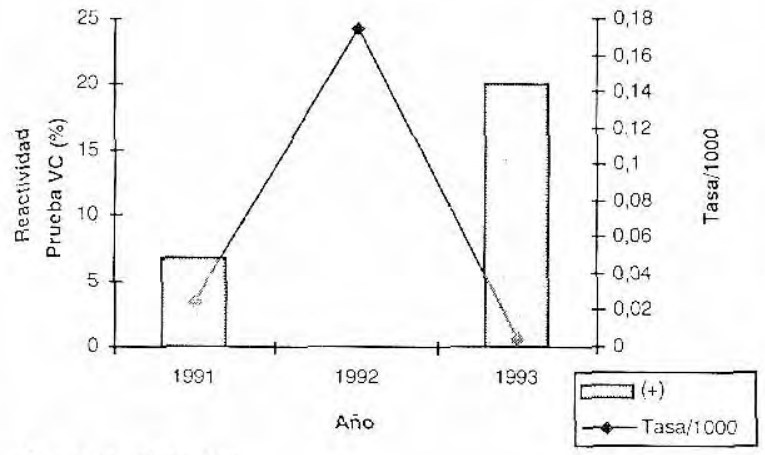

D: región Oriental

por la presencia de anticuerpos vibriocidas o por la memoria inmunológica presente en la mucosa intestinal $(2,19,20)$. Contrariamente, en áreas epidémicas, el cólera presenta una alta tasa en adultos y afecta a todas las edades por igual debido al bajo nivel de anticuerpos protectores en toda la población (21).

La población colombiana no había tenido contacto reciente con la bacteria debido a que la última epidemia se había informado hace 100 años (22). Por consiguiente, no se había realizado un estudio serológico a nivel nacional para determinar anticuerpos vibriocidas. Igualmente, se podía asumir que los anticuerpos vibriocidas no debían estar presentes en la población, lo cual se demostró en los estudios de seguridad e inmunogenicidad realizados con dos posibles vacunas en dos grupos de voluntarios $(5,6)$. En esos dos estudios, no se detectaron anticuerpos 
vibriocidas en los sueros previos a la inmunización; por tanto, esos datos se emplearon para establecer el punto de corte para la interpretación de los resultados en este estudio. Con el mismo propósito, se emplearon los resultados de los sueros obtenidos en la región atlántica dos meses antes de la aparición de casos de cólera en ella (sueros preepidémicos). Adicionalmente, la no reactividad de los sueros preinmunes y pre-epidémicos permitió, en nuestra experiencia, determinar la especificidad de la prueba vibriocida debido a que no ocurrieron las reacciones cruzadas descritas por la presencia de anticuerpos contra Brucella, Yersinia y Citrobacter(23).

El punto de corte establecido (mayor o igual a 80) es una dilución menor que los empleados en el área epidémica de Piura, Perú (17), y en México en un estudio de casos y controles (7). Contrariamente, el punto de corte empleado en este estudio para establecer una infección reciente (mayor o igual a 640) fue superior al establecido en los estudios anteriormente mencionados.

La distribución de los porcentajes de reactividad para las diferentes regiones en los tres años de estudio muestra una similitud con la forma de diseminación de la enfermedad en el país, la cual se inició en la región pacífica (Nariño), se extendió por la región andina y llegó a la región atlántica a finales de 1991. El descenso de los títulos vibriocidas se correlaciona con la cinética de los anticuerpos vibriocidas posterior a una infección (24); se observó que, en la región pacífica, los títulos empezaron a disminuir después del segundo año, $y$, en la región atlántica, el porcentaje de reactividad se incrementó en el segundo año y disminuyó en el tercero.

Al emplear la cepa de $V$. cholerae serotipo Ogawa en los sueros no reactivos con el serotipo Inaba, el porcentaje de reatividad se incrementó en $7 \%$; este hallazgo corrobora la importancia de realizar la técnica de anticuerpos vibriocidas con los dos serotipos para determinar el nivel de anticuerpos presentes. En México, se observó que existía variación entre los porcentajes de reactividad con los dos serotipos según el año; en 1991, el mayor porcentaje fue con el serotipo Inaba mientras que, en 1992, fue con el Ogawa, correlacionándose este hallazgo con el serotipo epidémico circulante (7).
Los anticuerpos vibriocidas pudieron determinarse en todos los grupos de edad en los dos géneros lo cual está de acuerdo con el hallazgo de casos de cólera y en lo descrito para las situaciones epidémicas $(25,26)$. Sin embargo, en este estudio se observó, inicialmente, una prevalencia mayor en el género masculino y dentro de él en los adultos, lo cual se correlaciona con las observaciones de la epidemia colombiana que mostró tasas de ataque más altas en hombres que en mujeres (datos del Ministerio de Salud); se asume, en general, que ésta es la población inicialmente más expuesta.

El aumento en el título vibriocida está relacionado con exposición a. V. cholerae 01; en un estudio de pacientes con cólera, se determinó, en la fase convaleciente, un porcentaje de seroconversión de $88 \%$ a los 7 días de iniciarse los síntomas, con un incremento de cinco veces el título inicial (18). En este estudio, los altos títulos vibriocidas de los sueros de pacientes con diagnóstico clínico de cólera, obtenidos en la fase convaleciente, estarian de acuerdo con esa observación aunque no se pudo determinar el porcentaje de seroconversión por no haberse obtenido sueros en la fase aguda de la enfermedad.

En este estudio, se demostró una alta prevalencia de infección, similar por género y por grupos de edad lo que señaló una mayor probabilidad de haberse infectado o de estar recientemente infectado al compararse con el resto de la población. Estos hallazgos demuestran la utilidad del método serológico tanto como herramienta de diagnóstico como en estudios epidemiológicos $(7$, 23, 24). Además, evidencian que la definición de caso clínico utilizada durante esa fase de la epidemia fue adecuada.

En áreas no endémicas de cólera, los porcentajes de reactividad de la prueba vibriocida varían de 3,6 a $5,2 \%$, en tanto que en las áreas endémicas los porcentajes informados son de $48,8 \%$ (27). En un estudio realizado en Antioquia, posterior al inicio de la epidemia, la prevalencia de anticuerpos vibriocidas fue de $11 \%$ en Turbo y de $7,8 \%$ en Arboletes (28). El porcentaje de reactividad total en los tres años de este estudio fue de $21,5 \%$ con un título de anticuerpos vibriocidas que determinó infección, de acuerdo con la definición establecida; 
al restringir el punto de corte, se estableció una infección reciente en $10 \%$ de la población estudiada. Es importante señalar que este estudio se realizó sobre una muestra de individuos que consultó a los hospitales; por esta razón, los resultados no pueden generalizarse a toda la población, pero, representa una muestra adecuada de los estratos que emplean los hospitales públicos, lo que en Colombia corresponde a una proporción de la población que va de 30 a $50 \%$ (29).

Otra de las aplicaciones de esta metodología es la de permitir realizar una vigilancia epidemiológica durante los períodos epidemiológicos silenciosos del cólera, para determinar los niveles de inmunidad de una población y ayudar a predecir una posible epidemia (2). En este momento, las regiones pacífica y atlántica han empezado a sufrir de nuevo brotes de cólera después de dos años de un relativo silencio epidemiológico. Dado que $V$. cholerae $\mathrm{O} 1$ tiene sitios ecológicamente favorables para su ciclo de vida libre y los casos de cólera se presentaron esporádicamente, una de las posibles explicaciones para estas nuevas infecciones es la disminución del título de anticuerpos, detectado en este estudio.

\section{Agradecimientos}

A las bacteriólogas Rosalba Molinares, Hospital Regional San Andrés, Tumaco; Denis Balaguera, Centro de Rehabilitación y Diagnóstico Fernando Troconis, Santa Marta; y a los servicios de salud del país por la recolección y envío de las muestras de suero empleadas en este estudio.

\section{Referencias}

1. Holmgren J, Clemens J, Sack DA. New cholera vaccines. Vaccine 1989;7:94-6.

2. Snyder JD, Allegra DT, Levine MM, Craig JP, Feeley JC, DeWitt WE, Blake PA. Serologic studies of naturally acquired infection with Vibrio cholerae serogroup O1 in the United States. J Infect Dis 1981; 143:182-7.

3. Sack RB, Barua D, Saxena R, Carpenter CJ. Vibriocidal and agglutinating antibody patterns in cholera patients. J Infect Dis 1966;116:630-40.

4. Centers for Diseases Control and Prevention and Pan American Health Organization. Laboratory methods for the diagnosis of Vibrio cholerae. Washington, D.C.: CDC y PAHO; 1994.
5. Concha A, Giraldo A, Castañeda E, Martínez M, de la Hoz F, Rivas F, et al. Seguridad e inmunogenicidad de la vacuna oral anticólera de células enteras muertas y de la subunidad $B$ recombinante de la toxina en Barranquilla, Colombia. Bol Ofic Sanit Panam 1995;29:103-11.

6. Castañeda E, Chinchilla M, Velandia M, de la Hoz F. Seguridad e inmunogenicidad de la vacuna oral anticólera CVD-103 HgR: estudio en 29 voluntarios. Biomédica 1995;15:49-53.

7. Gónzalez-Bonilla C, Valle-Valdez JG, Núñez-León A, Moguel-Pech L, Villanueva-Zamudio A. Seroepidemiología del cólera en México. Rev LatAmer Microbiol 1994;36:253-6.

8. Sánchez JL, Hayashi KE, Kruger HF, Meza R, English CK, Vidal W, et al. Immunological response to Vibrio cholerae $\mathrm{O} 1$ infection and and oral cholera vaccine among Peruvians. Trans R Soc Trop Hyg 1995;89:542-45.

9. Jerborn M, Svennerholm AM, Holmgren J. Gut mucosal, salivary and serum antitoxic and antibacterial antibody responses in Swedes after oral immunization with $\mathrm{B}$ subunit-whole cell cholera vaccine. Int Archs Allergy Appl Immun 1984;75:38-43.

10. Merritt C, Sack RB. Sensitivity of agglutinating and vibriocidal antibodies to 2-mercaptoethanol in human cholera. J Infect Dis 1970;121:s25-s30.

11. Cash R, Music SI, Libonati JP, Snyder MJ, Wenzel RP, Hornick RB. Responses of man to infection with Vibrio cholerae. I.Clinical, serologic, and bacteriologic responses to a known inoculum. J Infect Dis 1974;129:45-52.

12. Svernnerholm AM, Jonson G, Holmgren J. Immunity to Vibrio cholerae infection. In: Wachsmuth IK, Blake PA, Olsvik O, editors. Vibrio cholerae and cholera. Washington, D.C.: American Society for Microbiology; 1994:257-71.

13. Castañeda E, Muñoz N, de Vargas $\mathrm{Cl}$, Escalante M, de Galindo B, Castrillón L. Diagnóstico bacteriológico del cólera: actividades del Labotatorio Nacional de Referencia. Biomédica 1992;12:131-6.

14. Black RE, Levine MM, Clements ML, Young CR, Svernnerholm AM, Holmgren J. Protective efficacy in humans of killed whole-vibrio oral cholera vaccine with and without the B subunit of cholera toxin. Infect Immun 1987;55:1116-20.

15. Paul J, White C. Serological Epidemiology. New York: Academic Press; 1973:19-32.

16. Rothman K. Epidemiología moderna. Madrid: Ediciones Díaz de Santos; 1986:153-236.

17. Ries AA, Vugia DJ, Beingolea L, Palacio AM, Vásquez E, Wells JG, et al. Cholera in Piura, Perú: a modem urban epidemic. J Infect Dis 1992;166:142933. 
18. McCormack WM, Chakraborty J, Rahman ASMM, Mosley WH. Vibriocidal antibody in clinical cholera. J Infect Dis 1969;120:192-201.

19. Svernnerholm AM, Jertborn M, Gothefors L, Karim AMMM, Sack DA, Holmgren J. Mucosal antitoxic and antibacterial immunity after cholera disease and after immunization with a combined $B$ subunit-whole cell vaccine. J Infect Dis 1984;149: 884-93.

20. Levine MM, Black RE, Clements ML, Cisneros L, Nalin DR, Young CR. Duration of infection-derived immunity to cholera. J Infect Dis 1981;143:818-20.

21. Mosley WH, Benenson AS, Barui R. A serological survey for cholera antibodies in rural east Pakistan. 1. The distribution of antibody in the control population of a cholera-vaccine field-trial area and the relation of antibody titre to the pattern of endemic cholera. Bull Wld HIth Org 1968;38:327-34

22. Serpa F. Historia del cólera en Colombia. Biomédica 1992;12:95-101

23. Gangarosa EJ, DeWitt WE, Feeley JC, Adams MR. Significance of vibriocidal antibodies with regard to immunity to cholera. J Infect Dis 1970;121:s36s43.
24. Wasserman SS, Losonsky GA, Noriega F, Tacket CO, Castañeda E, Levine MM. Kinetics of the vibriocidal antibody response to five oral cholera vaccines. Vaccine 1994;12:1000-3.

25. Bendid A, Bougoudogo $F$, Messast $M$, Rezkallah D, Hamchi L, Bellouche Y, et al. Value of vibriocidal antibody research in endemic areas of Vibrio cholerae O1.Bull Soc Pathol Exot 1994; 87:337.

26. Savelev VN, Efremenko VI, Gnutov IN, Kiseleva TF, Bogdanov IK, Postovoi PP, et al. The evaluation of the vibriocidal antibody test in establishing a diagnosis of cholera or Vibrio carriage. ZH Mikrobiol Epidemiol Immunobiol 1992;11-12:55-7.

27. Felsenfeld O, Dutta NK. A serological survey of cholerafree and cholera-infected areas. J Trop Med Hyg 1972:209-12.

28. Galeano LA, Villegas EM, Loaiza IB, Cardona N. Perfil inmunológico para Vibrio cholerae en la población del área urbana de Turbo y Arboletes. Bol Epidemiol Antioquia 1995;20:46-52.

29. Pabón A. Demanda y utilización de servicios de salud. Bogotá: Instituto Nacional de Salud; 1991:46. 